\title{
APPLICATION OF VFDS FOR IMPROVING THE ENERGY EFFICIENCY OF INDUSTRIAL GRADE AIR COMPRESSOR
}

\author{
1. D Venkata Ramana*, 2. S. Baskar
}

1. Research Scholar, School of Electrical Engineering, Vel-Tech Dr RR \& Dr SR University, Chennai-600 062, India.

2. Professor, School of Electrical Engineering, Vel-Tech Dr RR \& Dr SR University, Chennai-600 062, India,

\author{
dvnkat@yahoo.co.in*, drbaskar@veltechuni.edu.in
}

\begin{abstract}
Variable Frequency Drive (VFD) has become an indispensable choice for industrial applications requiring finer control over the speed. VFD implementation comprises of a rectifier-inverterinduction motor. The inverter is usually built using Insulated Gate Bipolar Transistors (IGBTs) which can be operated at higher switching frequencies (in the order of a few KHz) that aids in precise speed control. On the other hand, the PWM Techniques are used to reduce harmonics thereby increasing the energy efficiency. With the VFD, operators can precisely adjust the motor speed to match the load requirements, which gives it an edge over constant-speed motors (which operate the motor at full speed always), thereby reducing the start-up current drawn, resulting in increase in the overall energy efficiency. In general, the techniques suggested for achieving energy efficiency involve huge initial cost and complex operations reducing the chances of adaptation. The usual pay-back period for the expensive installations can range from just a few months to less than three years for 25-to-250- horsepower models. [1] This paper presents a case study which involves deployment of a VFD for an industrial air compressor.
\end{abstract}

Keywords: Variable Frequency Drive, Air Compressor, Energy Conservation, Industrial Air Compressors, Retrofit VFDs.

\section{INTRODUCTION}

IEEE reports estimated that $60-65 \%$ of Induction Motors are used for centrifugal fans, pumps and compressors. These loads demand variation of fluid flow and historically conventional methods were employed to achieve this.

The improvements in manufacturing techniques of the power electronic devices resulted in fabricating compact and cost effective devices which has longer life and reduced maintenance. This resulted in widespread adaptation of these devices for building various equipment used as controllers for the drives.

The main component of a VFD is the controller and this comprises of a AC to DC converter, made of SCRs and an Inverter using IGBTs.

The inverter converts the DC link voltage to feed a variable-frequency, variable-voltage AC supply to the motor and can regulate the speed of an induction motor in the range of 10 to $200 \%$ which is possible by operating the IGBTs at a relatively high switching frequency. The inverter can also regulate the output voltage in proportion to the output frequency to provide a relatively constant ratio of $\mathrm{V} / \mathrm{f}$ to produce adequate torque. [2] The PWM techniques reduce the harmonics, aids in regulating the voltage and achieving smoother speed control. Reduction in harmonics help to improve the efficiency. Thus, the conventional controllers are being replaced by the VFDs.

This paper presents results of the experimental deployment which proves that the energy could be conserved in Air Compressors economically by using VFD.

\section{AIR COMPRESSOR}

Air Compressor is a mechanical device, that compresses the fluid (air) from the atmosphere, to a required pressure with the help of a prime mover (IM). Usually the Air Compressors are deployed outdoor, they require frequent maintenance and this is the reason for choosing 'Squirrel Cage Induction Motor' instead of other motors. There are diverse types of rotary air compressors available in market such as Screw, Vane type, lobe and scroll. Factors that affect the performance of compressors are: speed of rotation, pressure at suction, pressure at discharge and type of refrigerant being used. 
In a typical setup, the motor, which runs the compressor is directly connected to a constant electrical supply due to which the motor runs at a continuous speed regardless of the load requirement, resulting in wastage of energy. So, the main aim is to ensure that the motor only generates enough energy to power the compressor and no more, eliminating energy wastage. Studies have shown that a $20 \%$ reduction in motor speed can lead to a $50 \%$ energy saving. [3]

A Screw compressor with conventional drive was originally deployed and it is replaced with the VFD for the experiment.

\section{VARIABLE FREQUENCY DRIVE}

A 'Variable-Frequency Drive' is a type of adjustable-speed drive used in electro-mechanical drive systems to control the AC motor speed and torque by varying the motor input voltage and frequency. Major components of the VFD are the controller and the motor. The controller has sub-systems made of solid state power electronic devices comprising a rectifier bridge converter, DC link and an Inverter The speed control of the SCIM, is achieved by feeding from a power supply whose frequency and voltage can be varied. VFDs facilitate energy savings

By employing a VFD, voltage and frequency can be easily regulated, as per the demands of the load, through a simplified user input mechanism via panel controls. [4]

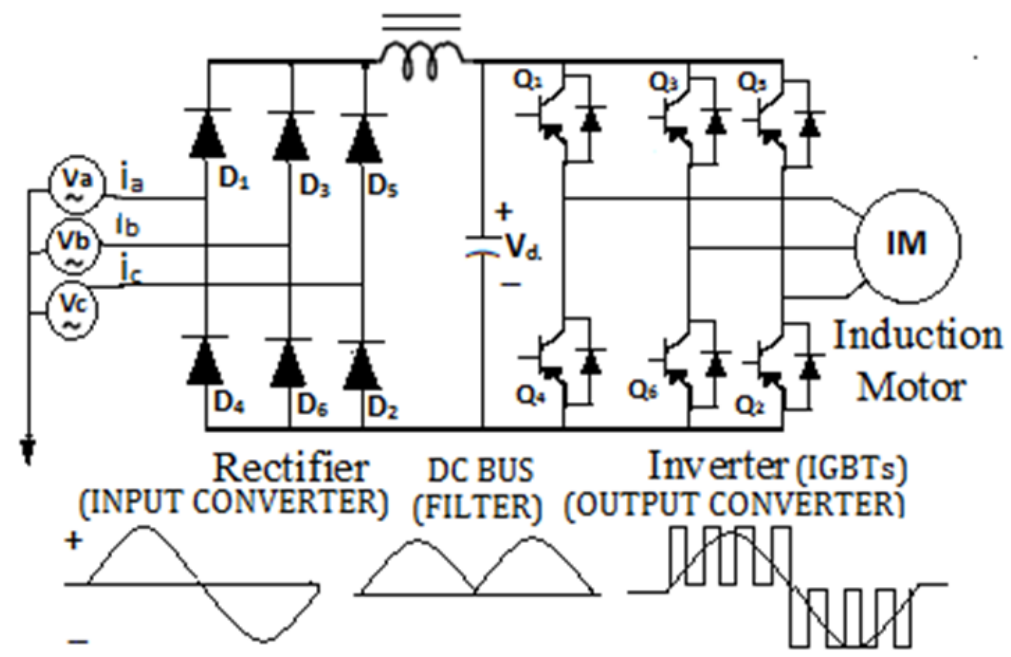

Fig.1. Block Diagram of VFD

\section{TYPES OF DRIVES}

Based on the mode of control, the industrial variable speed drives can be broadly classified as Mechanical, and Electrical. A brief description of few important drives is provided below:

\section{A. Mechanical Drives}

a. Adjustable sheave belt drive: These are designed to allow changes to the drive's shaft speed while motor speed is being fixed.

b. Clutch: It is a mechanical device that engages and disengages the power transmission. For example, a beltdriven engine cooling fan may have a heat-activated clutch.

c. Traction drive; Transmissions employing rolling-contact bodies are known as traction drives.

\section{B. Electrical Drives}

a. DC (rotating and solid state): speed control of DC motor is smoother if Ac to Dc converter is employed instead of resistances connected in series with the armature circuit.

b. Eddy-current clutch: This is an electromagnetic clutch in which torque is transmitted by means of eddy currents induced by a magnetic field set up by a coil carrying direct current in one rotating member.

c. Solid state AC drives: Inverter fed induction motor drive, which uses variable frequency and variable voltage to control the motor. 
d. Multi-speed motors: The booster windings are used with taps which allow the different voltages to the pole, creating different speeds in the motor.

\section{NEED FOR ADAPTATION OF VFD}

Following reasons make VFD a compelling choice for industrial applications:

a. Variable speed and Improved process control can be achieved without any additional alterations to standard IM setup.

b. Soft start, smooth acceleration and reduced starting voltage requirement, which limits the high in-rush current thereby reduces motor heating and stress eventually resulting in energy savings.

\section{FUNCTIONING OF THE VFD}

This section briefly explains the fundamental operating principle of the complete system.

\section{A. Basic Induction Motor Operation}

Air gap flux of an IM is governed by V/f characteristics. The speed of the rotor, $N$ is less than synchronous speed $N s$, the speed of rotating magnetic field developed by the stator. [5] The $N s$ is a function of the number of poles of the motor and supply frequency. This is given by

$$
N_{s}=\frac{120 f}{P}
$$

Whare, $N_{s}=$ synchronous Speed

$$
\begin{aligned}
& f=\text { Supply Frequency } \\
& P=\text { Number of poles }
\end{aligned}
$$

The speed of the rotor relative to that of the stator-rotating field is called as 'slip' $S$, which is expressed as a fraction of the synchronous speed.

$$
N_{s}=\frac{N_{s}-N}{N_{s}}
$$

The primary function of the motor is to provide torque, which makes the shaft / loads to rotate at the required speed.

a. The "torque" of an induction motor depends upon the flux in the air gap.

b. Further, flux is directly proportional to $V / f$, where $V$ is supply voltage and $f$ is the supply frequency. It can therefore be said that the torque $T$ is directly proportional to flux \& flux is directly proportional to $V / f$.

c. Thus, the torque producing capability of the motor at the rated / required speeds can be retained constant, by maintaining the $V / f$ ratio constant. varied.

In concise, to vary the speed of an induction motor the frequency of the supply to the motor should be

\section{B. Speed Control of Motor Using VFD}

The VFD controller consists of three main sections: 1. AC to DC converter, 2. DC Link and 3. Inverter. The AC to DC converter is usually a bridge converter which converts AC power from the mains to DC power. The DC link filters and provides a stable output which is fed to the inverter. Such a constant DC output enables the drive to perform better. Inverters use IGBTs to switch the DC bus on and off at a high frequency thereby producing a variable-voltage and variable-frequency AC power which is non-sinusoidal in nature which will be further subjected to PWM techniques to obtain a near sinusoidal output which can be fed to the IM.

The speed at which power devices switch on and off is the carrier frequency, also known as the switching frequency. The higher the switching frequency, the more resolution each PWM pulse contains. Typical switch frequencies are 3,000 to 4,000 times per second ( $3 \mathrm{KHz}$ to $4 \mathrm{KHz}$ ). To conclude, with the precise frequency and voltage control offered by the VFD, it becomes an indispensable choice. 


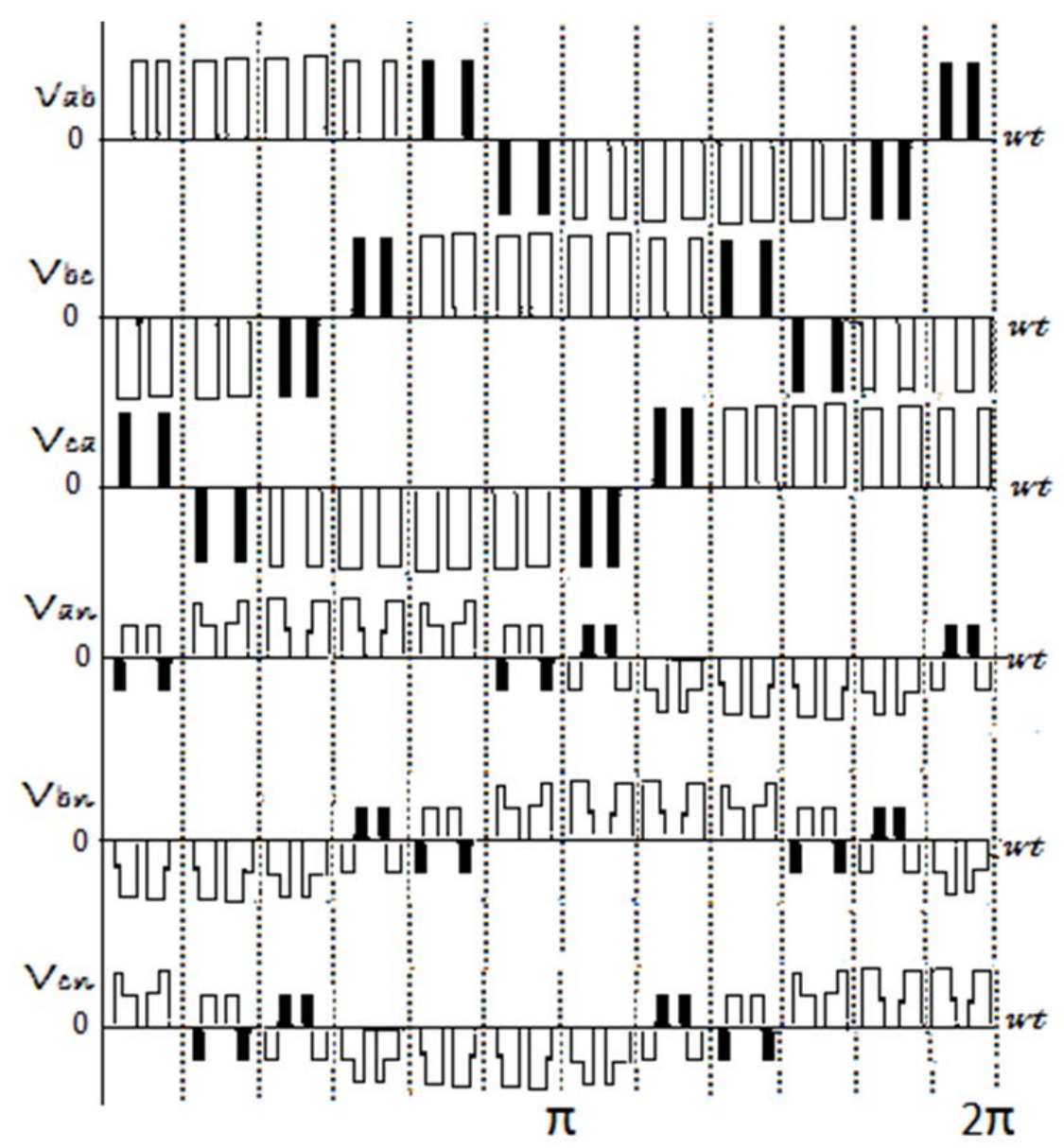

Fig.2. Three-phase Inverter output with PWM [6]

VII. EXPERIMENTAL SETUP AND RESULTS

\section{A. Setup}

The experimental readings were taken in H.B.L power system Ltd, Hyderabad, India. There were 10 air compressors categorized into two types which were observed and the details are:

TABLE I

DESCRIPTION OF COMPRESSORS

\begin{tabular}{|l|l|l|}
\hline Description & Type 1 & Type 2 \\
\hline Name & Chicago pneumatics & Chicago pneumatics \\
\hline Type & Screw & Screw \\
\hline Model & CPC -50 IVR & CPC -50 \\
\hline Capacity & $225 \mathrm{cfm}, 10 \mathrm{bar}$ & $225 \mathrm{cfm}, 10 \mathrm{bar}$ \\
\hline
\end{tabular}




\section{B. Observations}

TABLE II

READINGS WITHOUT VFD IN AIR COMPRESSOR

\begin{tabular}{|l|l|l|l|}
\hline S. No. & TIME & SPEED(RPM) & ENERGY(kwh) \\
\hline 1 & 10.15 & 2000 & 0.26 \\
\hline 2 & 10.30 & 2010 & 8.96 \\
\hline 3 & 10.45 & 1992 & 17.81 \\
\hline 4 & 11.00 & 2022 & 25.75 \\
\hline 5 & 11.15 & 2005 & 34.20 \\
\hline 6 & 11.30 & 1991 & 42.98 \\
\hline 7 & 11.45 & 2030 & 50.32 \\
\hline 8 & 12.00 & 1988 & 58.93 \\
\hline 9 & 12.15 & 2016 & 66.13 \\
\hline
\end{tabular}

The readings were taken in the Air Compressor with and without VFD. It has been observed that for 2 hours approximately per day energy consumed by the compressor incorporated with VFD was $26.22 \mathrm{kwh}$ and similarly energy consumed by the compressor without VFD was $33.07 \mathrm{kwH}$. So, energy conservation per hour/per compressor is $6.85 \mathrm{kwH}$. The readings are taken by FLUKE POWER QUALITY ANALYZER[Fig.3]

TABLE III

READINGS WITH VFD IN AIR COMPRESSOR

\begin{tabular}{|l|l|l|l|}
\hline S. No. & TIME & SPEED(RPM) & ENERGY(kwh) \\
\hline 1 & 10.15 & 2140 & 0.24 \\
\hline 2 & 10.30 & 1960 & 4.7 \\
\hline 3 & 10.45 & 2175 & 10.02 \\
\hline 4 & 11.00 & 2255 & 10.88 \\
\hline 5 & 11.15 & 2300 & 12.76 \\
\hline 6 & 11.30 & 2523 & 15.37 \\
\hline 7 & 11.45 & 2233 & 26.99 \\
\hline 8 & 12.00 & 1740 & 45.58 \\
\hline 9 & 12.15 & 1200 & 52.43 \\
\hline
\end{tabular}




\section{ENERGY SAVINGS CALCULATIONS}

Energy savings from variable-frequency drives can be significant. Variable-frequency drives can reduce energy use by as much as $30 \%$.

TABLE IV

ENERGY SAVINGS CALCULATIONS

\begin{tabular}{|l|l|}
\hline Yearly Energy Savings per Compressor & $59184 \mathrm{kWh}$ \\
\hline Energy Units Saved & 59184 units \\
\hline Cost of Energy per Unit & $\$ 0.09$ \\
\hline Cost Savings per Compressor (approximately) & $\$ 5,333.33$ per year \\
\hline Cost of VFD installation & $\$ 5,333.33$ \\
\hline Payback Period (approximately) & 1 Year \\
\hline Total Energy Savings per 10 Compressors per Year & $\$ 53,265.6$ \\
\hline
\end{tabular}

The installation cost of the VFD is recovered in the first year and from second year onwards there is a net annual saving of approximately $\$ 48000$ in energy.

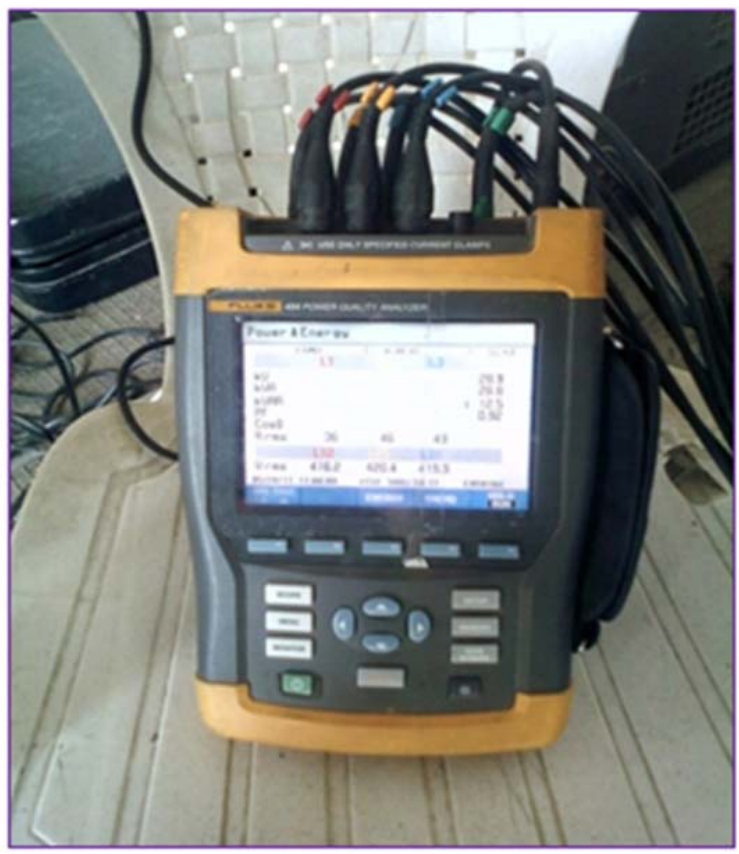

Fig 3. Fluke Power Quality Analyzer (Measuring Device, Courtesy: HBL Power Systems Ltd, Hyderabad)

\section{CONCLUSION}

The cost of VFD is high and the installation takes from 10 to over 70 labour-hours, depending on system size and complexity. The pay-back period for these drives can range from just a few months to less than three years for 25- to 250- horsepower models. Because each variable-frequency drive can drive more than one motor, some costs can be consolidated [7]. In addition, savings from reduced maintenance and longer equipment life contribute significantly to achieving long-term savings. Many electric utilities offer financial incentives that can reduce the installed costs of variable-frequency drive. 
The two most significant benefits from the evolution in technology have been that of cost and reliability, in addition to the significant reduction in physical size. With the widespread adaptation of the VFDs in industrial sector, there is a higher potential for the retrofits and new installations. Another factor is that VFDs saves energy more than $30 \%$ based upon several variables compared to traditional drives. [8] Additional benefits which are readily seen include: the reduction and/or elimination of motor starters, less stress on the AC motor windings and bearings, and a decrease in stress and wear on the pump or fan itself. This all equates to a smoother, longer lasting and more efficient operation process. However, it should be noted that VFDs are susceptible to dust contamination, and corrosion because of humidity in outdoor installations so, it is advisable use a NEMA 12 enclosure and a thermostatically controlled space heater if you place it where condensation is likely. [9]

So, from the above we can conclude that by incorporating VFD in an Air Compressor we can obtain:

- $\quad$ Easy setup and programming

- Less space requirement

- Better design and speed control

- Competitive edge (Easier retrofitting)

Payback period for the cost incurred is just less than a year.

\section{REFERENCES}

[1] "VFDs - Energy Efficiency Reference Guide", Natural Resources Canada, 2009. Technical application considerations including load characteristics and comparison with conventional control methods.

[2] Bose, B. K. Energy Scenario and Impact on Power Electronics in the 21st Century. PEIA 2011 - Workshop on Power Electronics for Industrial Applications and Renewable Energy Conversion. Doha, Qatar-12, 2011.

[3] www.gambica.org.uk/asset/249F4CBA-FB11-42EE-BCF57C6138B1D3A3/.

[4] Bose, B. K. (1980). Adjustable Speed AC Drive Systems. New York: IEEE Press. ISBN 0-87942-146-0.

[5] Robert S. Carrow Electrician's Technical Reference: Variable Frequency Drives.

[6] http://what-when-how.com/induction-motor/control-of-voltage-source-inverters-induction-motor.

[7] “Improving Motor and Drive System Performance: A Sourcebook for Industry", U.S. Department of Energy, 2008. A Technical Overview of Motor and Drive Systems, Performance Opportunities, Costs and Economics.

[8] VFD Tech Tool, New Jersey's Clean Energy Program. Spreadsheet that calculates overall facility-wide energy savings estimate for a range of facility types and multiple motors.

[9] Malcolm Barnes. Practical Variable Speed Drives and Power Electronics (Practical Professional Books)

\section{AUTHOR PROFILE}

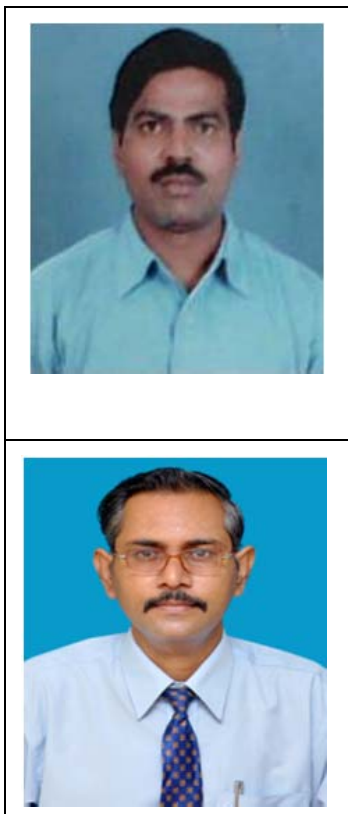

D Venkata Ramana received the B E(Electrical) degree from Vijayanagara Engineering College, Bellary, Karnataka, India 1995 and M Tech from NITK (Electrical and Electronics), suratkal, Karnataka, India in 2000. Currently he is pursuing his Ph. D research work at Vel-Tech Dr RR and Dr SR Technical University, Chennai. Area of research interests are Power electronics and drives, wavelets applications, microprocessor controlled drives, Fault diagnosing techniques of Electrical Machines, Wind Energy Systems and Traction drives.

Dr. S. Baskar was born in Cuddalore, India on February 3, 1974. He received his B. E (Electrical \& Electronics) from Annamalai University and M. Tech (Power Electronics) from Vellore Institute of Technology, India. He has completed his $\mathrm{Ph} . \mathrm{D}$ in FACTS controllers from Annamalai University. He is currently working as Professor in the Department of Electrical and Electronics Engineering, at Vel-Tech Rangarajan Dr. Sagunthala R\&D Institute of Science and Technology, Vel-Tech Dr. RR \& Dr. SR Technical University, Avadi, Chennai India. His research interests include Power Electronics, Control and Modelling of FACTS Controllers and its application to power system. 